Rev. High Pressure Sci. Technol., Vol. 7 (1998) 921 923

\title{
Explosive Welding of a Thin Metallic Plate onto a Ceramic Plate Using Underwater Shock Wave
}

\author{
K. Hokamoto, M. Fujita, and H. Shimokawa \\ Department of Mechanical Engineering and Materials Science, Kumamoto University, Kumamoto 860, Japan
}

\begin{abstract}
Thin metallic plate was welded onto a ceramic plate using regulated underwater shock wave. The thin metallic plate was accelerated about $900 \mathrm{~m} / \mathrm{s}$ by underwater shock wave and collided with ceramic plates, such as the $\mathrm{ZrO}_{2}$ ceramic plate. Bonding was achieved through intensive deformation at the collision point, but cracks were normally generated in the ceramic plate. The use of a cover plate with the metallic plate and other devices such as momentum traps was effective in eliminating cracks in the $\mathrm{Al} / \mathrm{ZrO}_{2}$ joint.

[underwater shock wave, explosive welding, metal/ceramic joining, interfacial phenomena, bonding of thin film]
\end{abstract}

\section{Introduction}

The explosive welding technique was developed in the 1950 s for joining metallic plates. It is now widely used in industry due to its high reliability of the bonding strength of the clad materials [1].

In this investigation, a new explosive welding technique in joining a thin metallic plate onto a ceramic plate was developed using underwater shock wave controlled loading. Explosive welding of a metallic foil to a ceramic plate was attempted more than twenty years ago [2]. These materials were joined only over an area of $4.83 \times 0.76 \mathrm{~mm}^{2}$ using an explosive whose weight was $0.7 \mathrm{mg}$. The results showed that the materials were bonded using no stand-off distance between metallic and ceramic plates. No interfacial phenomena and bonding condition were characterized. In these earlier investigations, the bonding mechanism might be based on a plastic deformation of aluminum on a roughened surface of the ceramic.

In this investigation, the use of underwater shock wave controlled loading is essentially important to accelerate the thin metallic plate very uniformly at a very high velocity greater than several hundreds $\mathrm{m} / \mathrm{s}$ as a means to generate a re-entrant jet ahead of the collision point within a certain stand-off distance between the metallic and ceramic plates [1], [3].

\section{Experimental procedure}

Figure 1 shows the experimental set-up developed for the present investigation. A high-explosive SEP produced by Asahi Chemical Industry, Co., Ltd. was used; the detonation velocity was $7 \mathrm{~km} / \mathrm{s}$, and the density was $1300 \mathrm{~kg} / \mathrm{m}^{3}$. A. 5 -mm-thick explosive was set with a steel reflector at a fixed inclined angle, $\alpha=20^{\circ}$, to decrease the horizontal collision point velocity, Vc, less than the value of the sound velocity of the materials to be welded [3]. Figure 2 shows the effect of the initial inclined angle of explosive $\alpha$ on the horizontal velocity Vc in considering the geometrical relationship [1]. The regulation of $\mathrm{Vc}$ was very important in obtaining plastic deformation at the collision point, and Fig. 2 shows that the increase in the inclined angle of explosive $\alpha$ can decrease Vc.

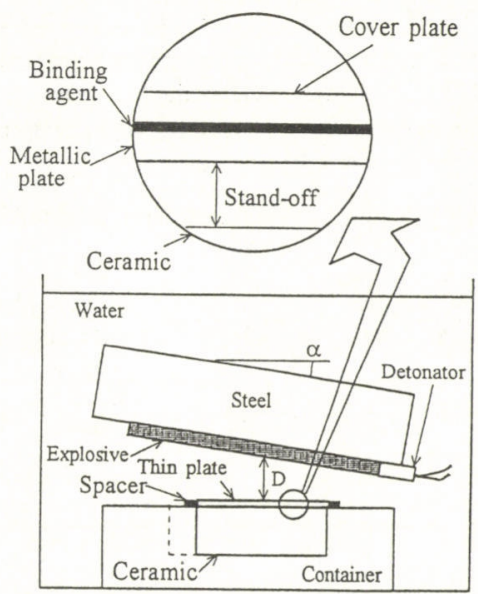

Fig.1. Experimental set-up for explosive welding of thin plate using regulated underwater shock wave.

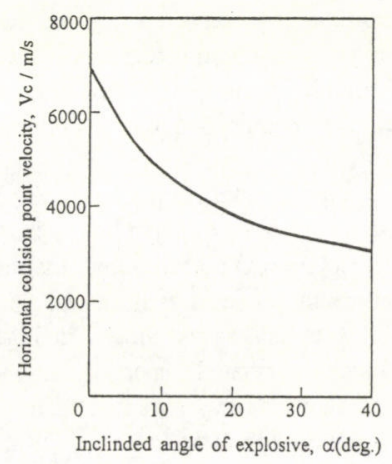

Fig.2. Effect of initial inclined angle of explosive $\alpha$ on horizontal collision point velocity Vc. 
Some experiments were conducted in water as shown in Fig. 1. A $0.1-\mathrm{mm}$-thick metallic plate was set on ceramic plates keeping a fixed stand-off distance of $0.5 \mathrm{~mm}$, and the gap was sealed against water. The metallic plate was sometimes covered with a stainless (0.1-mm-thick) or an aluminum $(0.3$ -mm-thick) sheet. These plates were bonded using an epoxy-resin based binding agent. The cover plate acts as a momentum trap to eliminate cracks due to the propagation of shock waves. The ceramic plate was fixed in a cast-aluminum container or in a epoxy resin which included $40-80$ mass $\%$ iron powders. The iron powders were mixed for the sake of increasing the density of the resin due to its small shock impedance. The distance between explosive and metallic plate D was fixed at $45 \mathrm{~mm}$.

The experimental conditions are listed in Table 1.

Table 1. Experimental conditions for explosive welding of thin metallic plate onto ceramic.

\begin{tabular}{|c|c|c|c|c|}
\hline Number & $\begin{array}{l}\text { Metal } \\
\text { plate }\end{array}$ & $\begin{array}{l}\text { Cover } \\
\text { plate }\end{array}$ & $\begin{array}{l}\text { Ceramic } \\
\text { plate }\end{array}$ & $\begin{array}{c}\text { Container } \\
\text { (thickness } / \mathrm{mm} \text { ) }\end{array}$ \\
\hline Al & $\mathrm{Al}(0.1)$ & - & $\begin{array}{c}\mathrm{ZrO}_{2} \\
(8)\end{array}$ & Aluminum \\
\hline A2 & $\mathrm{Al}(0.1)$ & $\mathrm{Al}(0.3)$ & $\begin{array}{l}\mathrm{ZrO}_{2} \\
(20)\end{array}$ & $\begin{array}{l}\text { Epoxy resin+ } \\
\text { Iron powder } \\
\text { [80 mass\%] }\end{array}$ \\
\hline $\mathrm{Cl}$ & $\mathrm{Cu}(0.1)$ & $\begin{array}{c}\text { SUS304 } \\
(0.1)\end{array}$ & $\begin{array}{l}\mathrm{ZrO}_{2} \\
(20)\end{array}$ & $\begin{array}{c}\text { Epoxy resin+ } \\
\text { Iron powder } \\
\text { [40 mass } \% \text { ] }\end{array}$ \\
\hline
\end{tabular}

\section{Experimental results and discussion}

Figure 3 shows the cross-sectional area obtained by an experiment in a case when the ceramic was set in a cast-aluminum container and without a cover plate. The plates were actually bonded at the interface, but a number of cracks were generated due to the propagation of strong shock waves in the ceramic. It is expected that the thermal history during the casting of aluminum decreases the mechanical property of the ceramic. Some pores were observed over the interface between the ceramic and the cast-aluminum due to their low wettability.

Figure 4 shows experimental results using zirconia ceramic which is bonded with thin copper plate. In this case, a stainless steel cover plate was placed above the metallic plate. The experimental results showed that the number of cracks decreased due to its toughness as shown in Fig. 4 (a), but there still exist cracks generated especially in the interfacial area. The interface showed wavy structure as found in Fig. 4 (b), which was generated due to a fluid-like behavior normally observed in explosively welded metallic plates [1]. The formation of a wave structure induced these cracks due to a large deformation in the ceramic. The cracks were actually initiated from the bottom of the fluctuation as shown in Fig. 4. The microstructure shown in Fig. 4 (b) suggested the melting of the reacted interfacial zone. The area was mainly composed of fused copper with a small amount of crushed ceramic as indicated by arrows in Fig. 4 (b). Such a microstructure suggests that the bonding mechanism is based on the formation of a metal-jet, which is well-known as a fundamental mechanism of explosive welding.

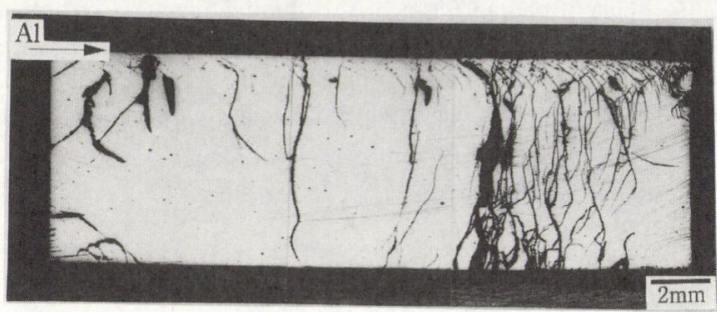

Fig.3. Cross-sectional area of explosively welded sample (\#A1) fixed in cast-aluminum container without using cover plate.

(a)

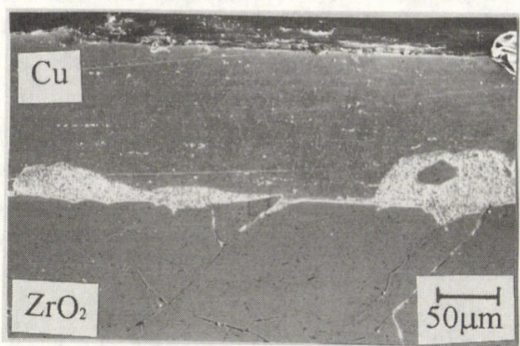

(b)

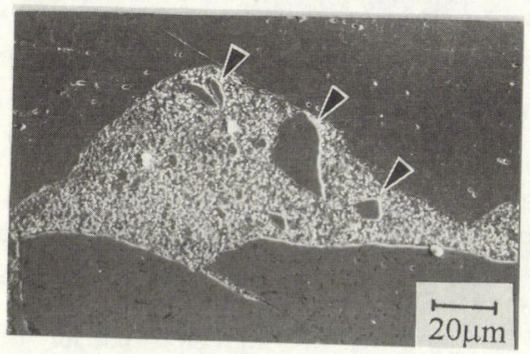

Fig.4. Cracks generated at interface (a), and microstructure in explosively welded $\mathrm{Cu} / \mathrm{ZrO}_{2}$ (experiment \#C1).

Experiment \#A2 showed remarkable improvement in decreasing the number of cracks as shown in Fig. 5 (a). In this experiment, a zirconia block $\left(30^{1} \times 10^{w} \times 30^{4} \mathrm{~mm}^{3}\right)$ was also placed as a momentum trap next to the zirconia ceramic 
to be bonded at the opposite side of the detonator as illustrated with dashed line in Fig. 1. The interfacial microstructure is shown in Fig. 5 (b). The interface exhibited planar structure, but the bonding was strong enough not to be peeled off through the bending test. In this experiment, the impact velocity to the normal direction $\mathrm{Vp}$ was estimated at about $900 \mathrm{~m} / \mathrm{s}$, and the velocity was greater than the velocity for the explosive welding of metallic plates, which was about 300 to $800 \mathrm{~m} / \mathrm{s}$ [3]. Also, the impedance matching method gave us the shock pressure of about 7.3 GPa [4].

It is essentially important to obtain such a planar interface in a case when one of the bonded materials is brittle. In the bonding of $\mathrm{Al} / \mathrm{ZrO}_{2}$, a formation of the planar interface is expected due to the difference in their density and flow strength [5],[6]. In the case of the explosive welding of an amorphous film onto a steel plate, a lower limit of the explosive welding condition was chosen to obtain the planar interface [7]. The existence of the fluctuation at the interface induces a possibility in generating cracks at the amorphous film. In our experiment, the predominant flow of aluminum with zirconia enables us to join these materials showing a planar interface under the explosive welding mechanism [1].

(a)

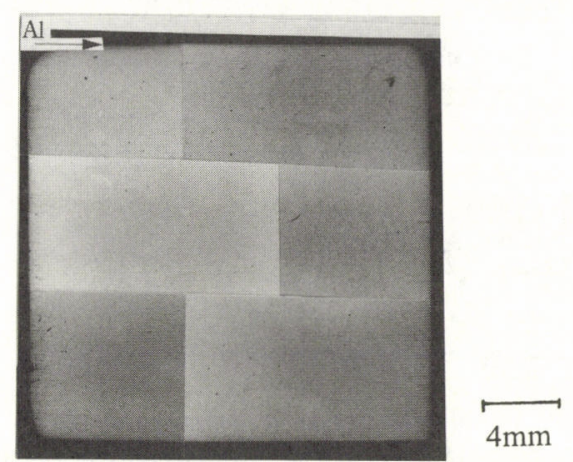

(b)

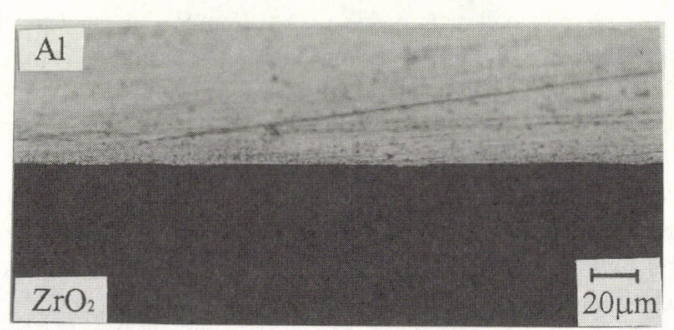

Fig.5. Cross-sectional area of explosively welded $\mathrm{Al} / \mathrm{ZrO}_{2}$ (\#A2) fixed in epoxy resin with cover plate (a), and its interfacial microstructure (b).

\section{Conclusions}

Thin metallic and ceramic plates were welded using regulated underwater shock wave. Under moderate experimental conditions, $\mathrm{Al} / \mathrm{ZrO}_{2}$ was successfully welded without cracks using a cover plate above the metallic plate and some other blocks as momentum traps, also using a ceramic container made by epoxy resin mixed with iron powders. In the welded material successfully obtained without cracks, the interface showed a planar structure, but showed good bonding based on the explosive welding mechanism.

The experiments were conducted in the High Energy Rate Laboratory, Kumamoto University with the assistance of $\mathrm{Mr}$. Y. Ishitani of the Laboratory.

\section{References}

[1] B. Crossland, Explosive Welding of Materials and its Application, Oxford Science Publications, New York, 1982.

[2] J.W. Shaffer, B.W. Cranston and G. Krass, Proc. 5th Int. Conf. on High Energy Rate Fabrication, 4.12 (1975).

[3] K. Hokamoto, M. Fujita, T. Ono, B. Shao and Z. Liu, Metallurgical and Materials Applications of Shock-Wave and High-Strain-Rate Phenomena,(Eds. L.E. Murr, K.P. Staudhammer and M.A. Meyers), Elsevier, Amsterdam, pp. 831, 1995.

[4] M. A. Meyers, Dynamic Behavior of Materials. Wiley-Interscience, New York, pp.179, 1994.

[5] K. Hokamoto, T. Izuma and M. Fujita, Metall. Trans, 24A, 2289 (1993).

[6] K. Hokamoto, A. Chiba and M. Fujita, Composites Engineering, 5, 1069 (1995).

[7] D.J. Vigueras, O.T. Inal and A. Szecket, Metallurgical Applications of Shock-Wave and High-Strain-Rate Phenomena, (Eds. L.E. Murr, K.P. Staudhammer and M.A. Meyers), Dekker, New York, pp.927, 1986. 